\title{
SELF-COMPACTING CONCRETE
}

\author{
HOW TO PRODUCE IT? \\ الخرسانة ذاتية اللامك - كيف ثنتج ؟
}

by

\author{
Mahmoud Imam \\ Associate Professor, Structural Engineering Dept., Mansoura University.
}

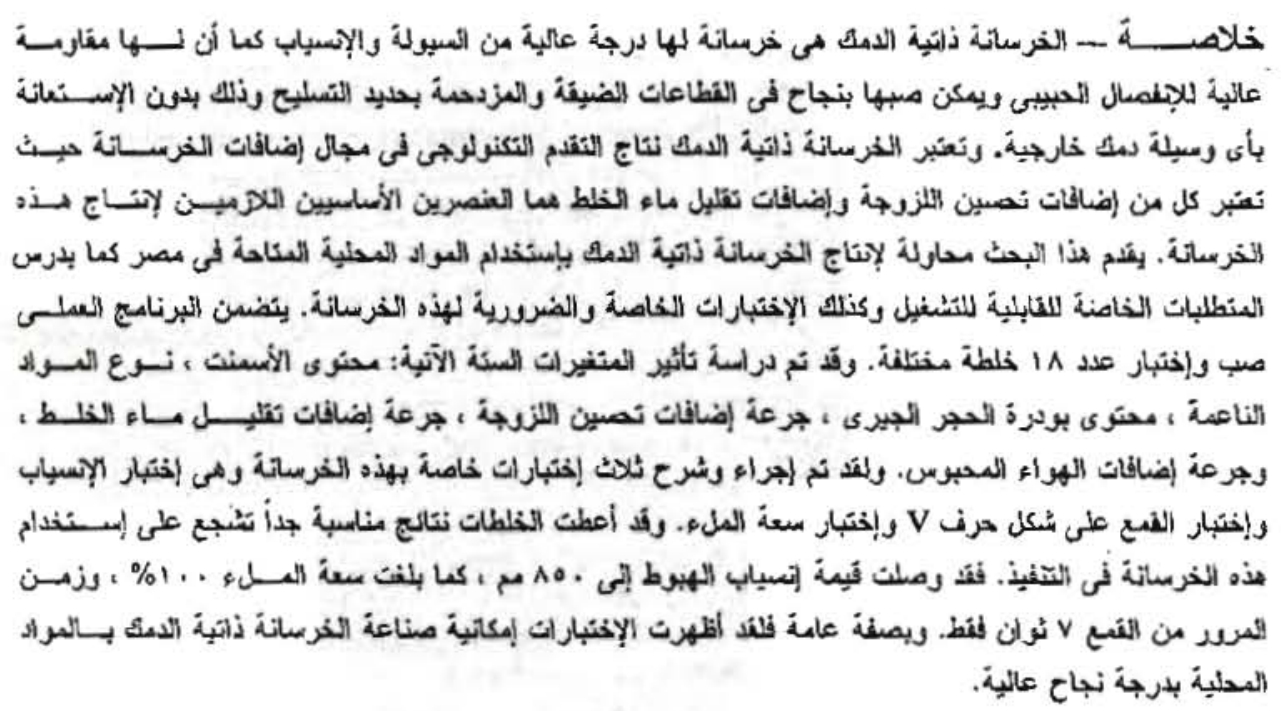

ABSTRACT - Self-Compacting Concrete (SCC) is a new type of concrete that can be spread in heavily congested regions under its own weight, and without vibration. It has excellent deformability and high resistance to segregation and bleeding. SCC is a result of the technological advancement in the area of concrete admixtures. This paper presents an attempt to produce SCC from the available materials in Egypt and investigates the workability requirements and tests of SCC. The experimental program consists of casting and testing eighteen SCC-mixes. Six different parameters are considered as; cement content, type of fine materials, content of limestone powder, dosage of viscosity-enhancing admixtures, dosage of air-entraining admixtures, and dosage of superplasticizers. The test resuits indicated that viscosity-enhancing admixture together with the new generation superplasticizer based on a modified polycarboxylic-polyether are the keystone for producing SCC. Three main tests which differentiate SCC from ordinary concrete were carried out and explained in this paper. These tests are slump-flow test, V-funnel test, and filling-capacity test. SCC-mixes provided slump flow up to 850 $\mathrm{mm}$, filling capacity up to $100 \%$, passing time up to $7 \mathrm{sec}$, and compressive strength up to $363 \mathrm{MPa}$ These results are quite appropriate for using SCC in any construction site. It is believed that SCC is a promising construction material in the near future.

KEYWORDS -... Seif-compacting concrete, flowable concrete, viscosity-enhancing admixture, air entertainment, slump flow, filling capacity test, V-funne! test, segregation, bleeding, superplasticizer, limestone powder. 


\section{INTRODUCTION}

Factors affecting the workability of a coocrete depend mainly on the type of construction, methods of placing and compacting, the complexity of form shape, and the degree of reinforcement congestion. In most reinforced concrete members with high ratio of reinforcing bars such as mat foundations and structural frame, there is an increasing need to use high flowable concrete to insure proper filling of formworks. When the concrete is a conventional concrete, then the vibration becomes an important part of the business. More vibrations can lead to segregation, bleeding, and blockage of the concrete when flowing across narrow spaces between reinforcement. As a result, improper bond to reinforcing steel and inadequate mechanical properties and durability may be attained. In such a case, Self-Compacting Concrete can be a solution.

The original idea of self-compacting concrete was published by the research team of professor Okamura at the University of Tokyo, Japan [1-3]. In their research, this concrete was called high-performance concrete (HPC). Some European and Canadian researchers insisted that the term "bigh performance" should refer only to hardened concrete and that the concrete with high fluidity proposed in Japan should be excluded from HPC and it was then called "SelfCompacting Concrete (SCC)", for which RIEEM organized a new committee [4]. Since then, several researchers all over the world have concerned with the investigation and production of SCC [5-13]. However, the development of SCC is a result of the technological advancement in the area of concrete admixtures. SCC is a new type of concrete that has excellent deformability and high resistance to segregation and bleeding. It can be spread in heavily congested regions under its own weight, and achieve good consolidation without vibration. It was employed in several construction projects [14-18].

SCC is obtained by the addition of a new generation superplasticizer which is based on a modified polycarboxylic polyether. A viscosity-enhancing agent is necessary to obtain adequate segregation resistance. The use of high content of fine materials such as limestone powder, granulated blast furnace slag powder, and/or silica fume or fly ash is also required. Limited coarse aggregate content is also advisable. The procedure to design the required SCC-mixture is totally different from that of conventional concrete, since segregation resistance and flowability characteristics have priority over the concrete strength. However, the main advantages of SCC are:

- Easily placed in thin-walled elements or elements with restricted access.

- Reduced noise and vibration during placement.

- Results in more durable concrete.

- Less leveling and better appearance on concrete surface.

- More concrete placement in less period of time.

- Very flowable concrete, no need to add any water in the job site.

- Cost savings through reduced equipment and less labor.

This paper presents an attempt to produce SCC from the traditional materials in Egypt and investigates the workability requirements and tests of SCC. 
Table I Constituents of Different Trial Batches of Self-Cowpacting Concrete.

\begin{tabular}{|c|c|c|c|c|c|c|c|c|c|c|c|}
\hline \multirow{3}{*}{ Mix } & \multicolumn{11}{|c|}{ Mjx Proportions for About One Cubic Meter of Self-Compacting Concrete } \\
\hline & \multirow{2}{*}{$\begin{array}{c}\text { Cement } \\
\mathrm{kg}\end{array}$} & \multirow{2}{*}{$\begin{array}{l}\text { L.S.P. } \\
\mathrm{kg}(\%)\end{array}$} & \multirow{2}{*}{$\begin{array}{c}\mathrm{F.S} \\
\mathrm{kg}(\%)\end{array}$} & \multirow{2}{*}{$\begin{array}{c}\text { Sand } \\
\mathrm{kg}(\%)\end{array}$} & \multicolumn{2}{|c|}{ Gravel } & \multirow{2}{*}{$\begin{array}{l}\text { HRWR } \\
\mathrm{kg}\end{array}$} & \multirow{2}{*}{$\begin{array}{l}\mathrm{VEA} \\
\mathrm{kg}\end{array}$} & \multirow{2}{*}{$\begin{array}{c}\mathrm{AEA} \\
\mathrm{gm}\end{array}$} & \multirow{2}{*}{$\begin{array}{c}\text { Water } \\
\mathrm{kg}\end{array}$} & \multirow[t]{2}{*}{ wis } \\
\hline & & & & & $\operatorname{kg}(\%)$ & $\mathrm{m}^{3}$ & & & & & \\
\hline M! & 450 & $0(0)$ & 0 & $630(35)$ & 1170 & 70 & 9 & 2.25 & 0 & 176.2 & 0.39 \\
\hline $\mathrm{M} 2$ & 40 & 090 & 0 & 5) & & & 9 & & & & \\
\hline $\mathrm{M3}$ & 450 & 180 & 0 & 10 & & & 9 & & & .5 & 47 \\
\hline M4 & 450 & 270 & 0 & 0 & 90 & 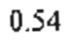 & 9 & & 0 & 7.5 & 53 \\
\hline M5 & 450 & 360 & 0 & 630 & 81 & 0 . & 9 & & 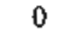 & 271.5 & 0.60 \\
\hline M6 & 450 & 450 & 0 & 630 & & 04 & 9 & & 0 & 252.5 & 0.56 \\
\hline M7 & 45 & 450 & 0 & 630 & & 0 & 9 & 0.0 & 0 & 202.5 & 0.45 \\
\hline M8 & 400 & 282 & 0 & 660 & & & 8 & 2 & 0 & 225.0 & 0.56 \\
\hline M9 & 45 & 0( & $00(1$ & 630 & 90 & 0.54 & 9 & 2.2 & 0 & 1.5 & 0.49 \\
\hline M10 & 45 & 270 & $\therefore$ & 630 & 90 & 0.5 & 12 & 0. & 0 & 02.5 & 0.45 \\
\hline $\mathrm{Ml}$ & 45 & 270 & 0 & 630 & & 0 & 12 & 2.2 & & 02.5 & 0.45 \\
\hline $\mathrm{M} 12$ & 45 & 270 & 0 & ) & 90 & 0.5 & 12 & 45 & 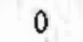 & 50.0 & .56 \\
\hline M13 & 45 & 270 & 0 & ) & & 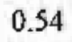 & 9 & & 0 & 54.5 & 0.57 \\
\hline M14 & 45 & 270 & 0 & 5) & & 4 & 9 & 6.75 & 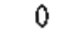 & 275.0 & 0.61 \\
\hline Mls & 450 & 2700 & 0 & $630(35)$ & & 0.54 & 9 & 0.0 & 225 & 237.2 & 0.53 \\
\hline M.6 & 450 & $270(15)$ & 0 & $630(35)$ & $900(50)$ & 0.54 & 9 & 2.25 & 225 & 241.9 & 0.54 \\
\hline M17 & 450 & 270( & $\dot{0}$ & $630(35)$ & $900(50)$ & 0.54 & 9 & 4.50 & 225 & 267.5 & 0.59 \\
\hline M18 & 450 & $270(15)$ & 0 & $630(35)$ & $900(50)$ & 0.54 & 9 & 4.50 & 450 & 275.0 & 0.61 \\
\hline \multicolumn{6}{|c|}{$\begin{array}{l}\text { L.S.P is a Limestone Ponder } \\
\text { HRWRA is a High Range Water-Reducing Admixture } \\
\text { VEA is a Viscosity-Enhancing Adruixture }\end{array}$} & \multicolumn{5}{|c|}{$\begin{array}{l}\text { F.S. is a Fire Sand } \\
\text { w/c is Water-Cement Ratio } \\
\text { AEA is an Ajr-Entraining Adnixture }\end{array}$} & \\
\hline
\end{tabular}

\section{OB.JECTTVES}

The main objectives of this paper are:

1 - To provide guidelines for proportioning SCC with local materials in Egypt.

2- To highlight the workability requirements needed to achieve self compaction.

3- To present some tests that can be used to evaluate deformability, filling capacity, and stability of SCC.

It is worth meotioning that, the properties of hardened phase of SCC are beyond the scope of this paper and wili be published in the near future.

\section{EXPERIMENTAL INVESTIGATION}

\section{Test Program}

The experimental program consists of casting and testing eighteen SCC mixes. The composition and proportioning of different concrete mixes are given in Table 1. The test program was designed and anranged to determine the effect of six different parameters as; cement content, type of fine materials, content of lime-stone powder, dosage of viscosityenhancing admixtures, dosage of air-entraining admixtures, and dosage of superplasticizers. Figure (1) gives an illustration for these variables. 
Ordinary portland cement (OPC; ASTM Type I) with contents of 400 , and $450 \mathrm{~kg} / \mathrm{m}^{3}$ was adopted in this study. The fine aggregate was natural sand with a fineness modulus of 247 , while the coarse aggregate was round gravel with $18-\mathrm{mm}$ size. Two extra types of finer materials were used; natural fine sand with a fineness modulus of 1.58 , and lime-stone powder with $55 \%$ of total weight passed sieve size $0.125 \mathrm{~mm}$. Viscosity-Enhancing Admixture (VEA) in the form of water soluble polymers was used to increase the cohesion of concrete mixes. It was supplied as a fine light brown powder with bulk density of $0.6 \mathrm{~kg} / \mathrm{liter}$. In addjition to a reference mix without VEA, three dosages of VEA were investigated as 0.5 , 10 , and $1.5 \%$ by weight of cement $A$ new generation superplasticizer based on polycarboxylate/polyether technology was used. It is a chloride free and supplied as an opaque white to pale amber coloured water-based liquid. This new generation superplasticizer acts on the cement particles to defloculate and disperse them and, unlike conventional superplasticizer, maintains the dispersion for extended periods. It provides a very powerful fluidifying effect which can be used to facilitate reductions in the water content of the concrete mix. Aluminum powder with a high degree of chemical reactivity was used to generate hydrogen bubbles in the concrete and hence, the deformability of the concrete increases. Aluminum powder is a metallic material with specific surface area of about 1000 $\mathrm{cm}^{2} / \mathrm{gm}$. The water/cement ratio of different mixes varied from 0.39 to 0.61 depending on the content of cement and different admixtures.

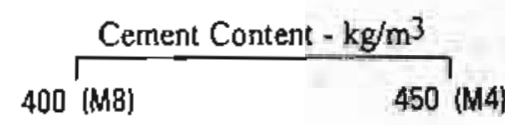

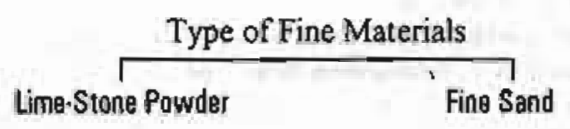

Lime-Stone Powder Fine Sand

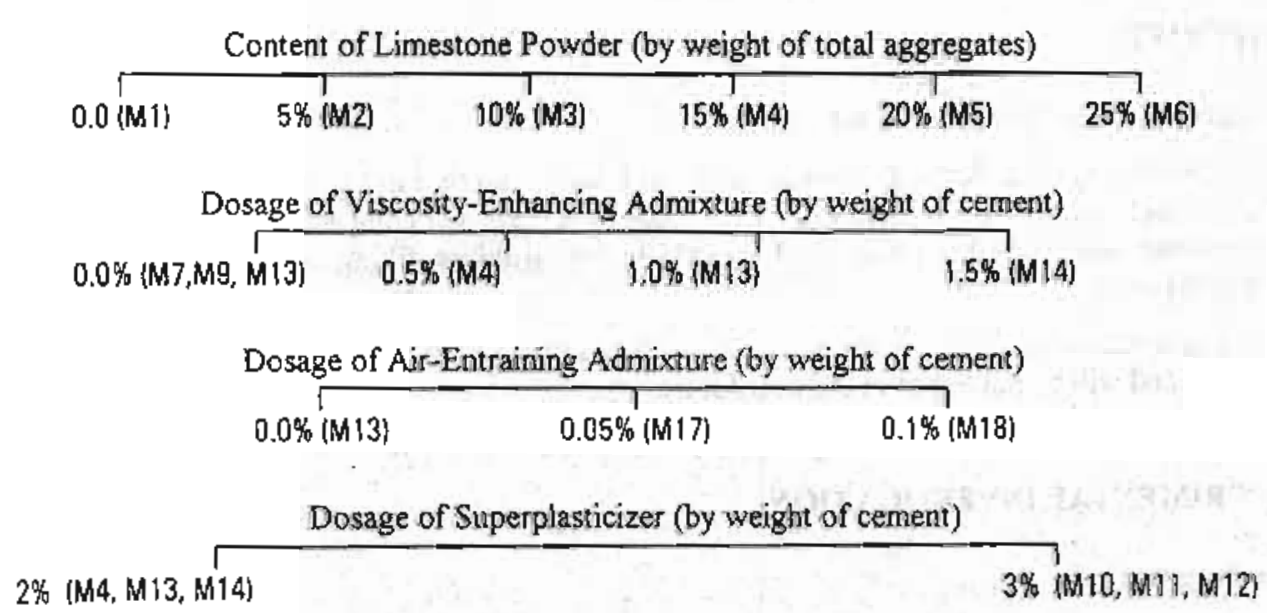

Fig. (1) Test Program. 


\section{Mix Design and Proportioning}

When proportioning SCC mixes, the basic considerations are the selection of a combination of materials that will produce excellent deformability, adequate resistance to segregation, and high filling capacity and flow around obstructions without blockage. These contradicting properties are difficult to attain. However, there was a general consensus that each SCC raix has to be designed on its own merit and cenainly there are matters which are considered for proportioning SCC and should be pointed out [5-8]. Among these matters:

1- To rectuce inter-particle friction, well graded powder with a content of about 15 to $20 \%$ of total aggregates should be used. Limestone powder is usable.

2- To increase the deformability of the mix, coarse aggregate content should be as low as possible.

3- Small size of coarse aggregate particles is recommended to minimize the risk of blockage. Maximum aggregate size is limited up to 20 mro.

4- Balanced water/cement ratio with high-range water-reducing admixture are nectssary. Polycarboxylate-polyether based superplasticizer is preferable.

5. To improve stability and prevent segregation, viscosity-enhancing admixture is required. The typical dosage of viscosity-enhancing admixture is $1 \%$ by weight of cement.

6- Increase the dosage of viscosity-enhancing admixture to minimize bieeding of $\$ \mathrm{CC}$.

7- Air-entraining admixture may be carefully added to enhance the deformability of concrete. When $\mathrm{SCC}$ with high strength is required, air-entraining admixture is not advisable.

8- The content of cement and cementitious materials should be in the range from 400 to 500 $\mathrm{kg} / \mathrm{m}^{3}$.

It can be noted that the design of SCC-mix totally differs from that of traditional concrete, since in SCC the properties of fresh concrete have the priority over other properties. The complete procedures for mix design of SCC are explained in Fig. (2).

\section{Tests and Procedures}

Concrete mixes were designed, treated, and controlled under the same conditions. The following key tests which differentiate SCC from ordinary concrete were carried out on the fresh-SCC:

Slump Flow Test .. The conventional slump test was used to determine the consistency of fresh concrete. The free deformability of SCC is also determined by measuring the slump flow. This test measures the ability of SCC to flow into all the spaces within the formwork under its own weight. Slump flow is determined by measuring the mean of two orthogonail diameters of the concrete base following the removal of the slump cone as shown in Fig. (3) It is one of the most popular methods of evaluating the flowability of SCC, both in laboratory and construction sites due to its ease of operation. This requires that the mix should have a high deformability, without excessive plastic viscosity. However, slump-flow test can not evaluate concrete's passage through reinforcement bars

V-Funnel Test.. This test has been proposed for measuring deformation rate of SCC. It is a simple mean of evaluating the ability of concrete to pass through spaces [Fig. (4)]. The facility of concrete to change its path and spread through a restricted area without blockage is 


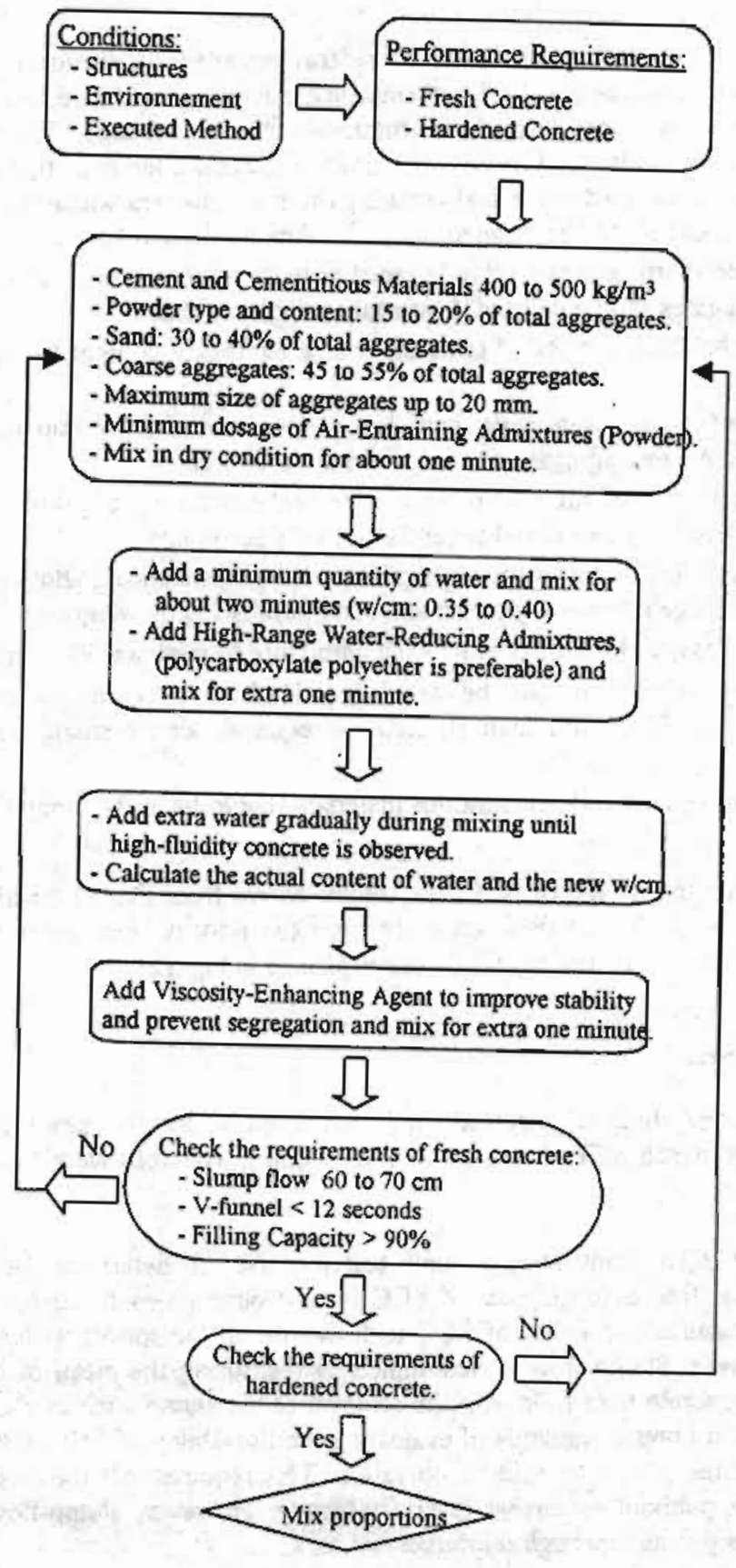

Fig. (2) Procedure for Mix Design of SCC. 
measured by $V$-funnel test. After filling the funnel with concrete to its top edge, the outlet gate was opened and the time required for the concrete to flow out is measured. This time is defined as the time between the removal of the outlet gate and the tione when the light becornes visible from the bottom

Filling Capacity Test .. The filling-capacity box shown in Fig. (4), is used for assessing SCC for very heavily reinforced structures and difficult formwork shapes. This test evaluate selfcompactability in terms of the concrete height after passing through parallel congested bars. The filling-capacity apparatus is a box with dimensions of $300 \times 250 \times 500 \mathrm{~mm}$. A number of 35 closely-spaced-smooth horizontal bars are used to evaluate the filling capacity of the concrete through the restricted sections. The concrete is placed from the top of the unreinforced part with a constant rate. The concrete flows under its own weight anong the closely spaced bars. This is continued until the concrete reaches a height of $250 \mathrm{~mm}$ in the unreinforced section. The filling capacity percentage is calculated as the ratio of $\mathrm{hx} 100 / 250$ where $h$ is the height in $\mathrm{mm}$ of concrete at the end of reinforced part as shown in Fig. (4).

SCC was cast and placed in cube specimen under its own weight and without any vioration. For measuring the compressive strength of $\mathrm{SCC}, 150$-mm cube specimens were made. All the test specimens were demolded after 24 hours and then submerged under water until tested (temperature: $20 \pm 2^{\circ}$ ). For each test, the average results of three specimens was determioed

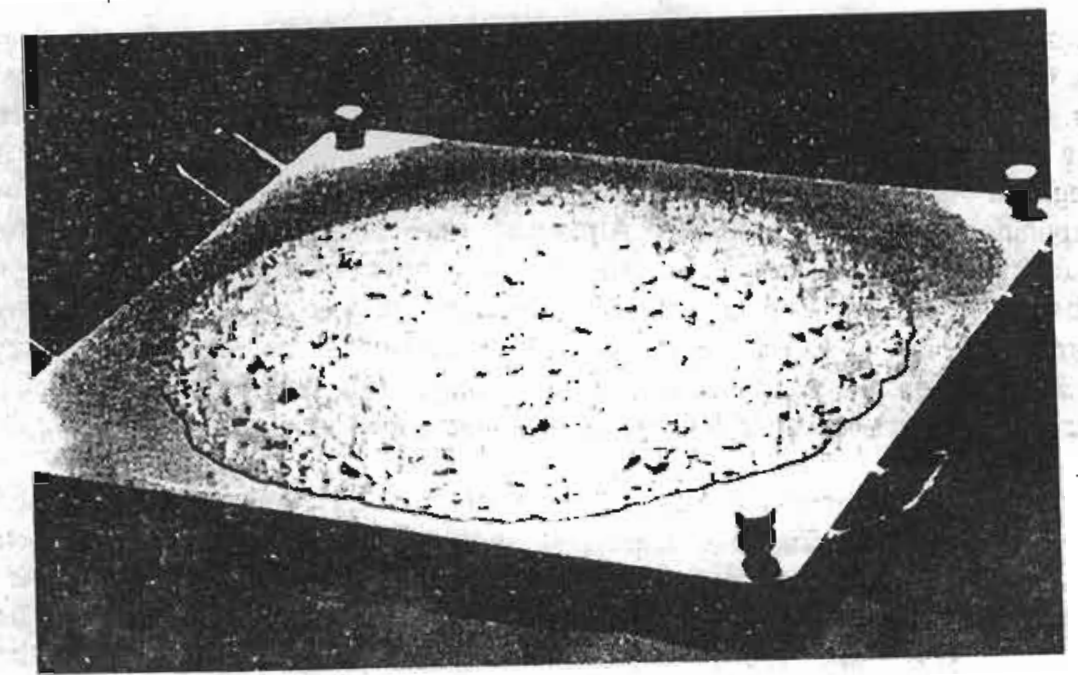

Fig. (3) Slump Flow of SCC. 

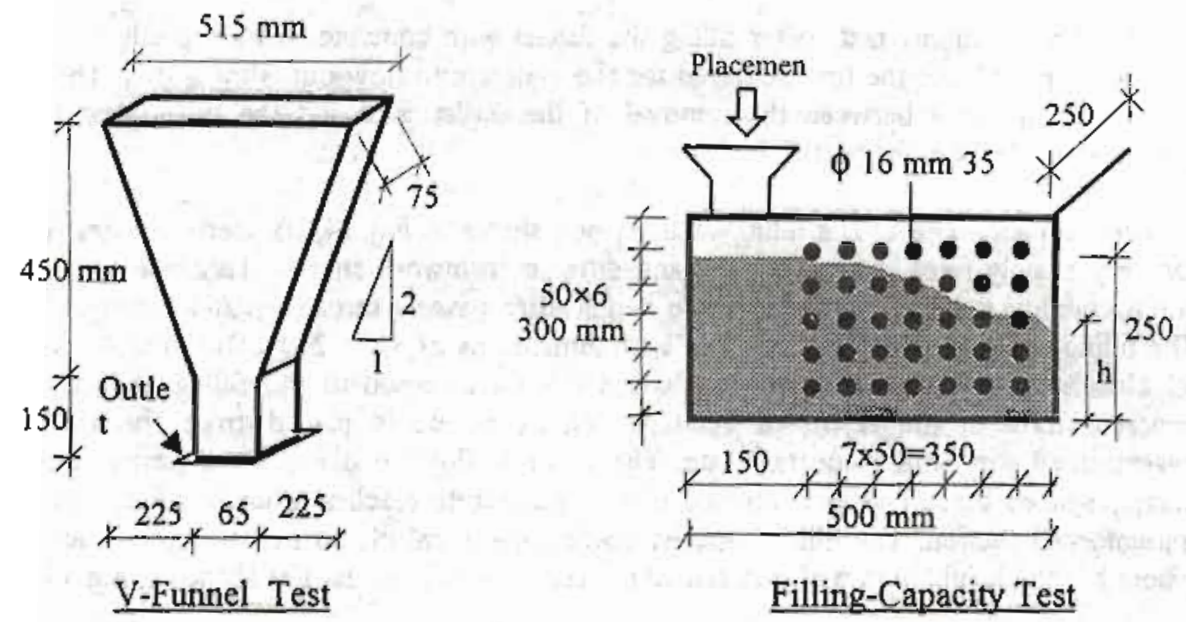

Fig. (4) Main Tests for Measuring the Properties of fresh-SCC.

\section{WORKABRITY REQUIREMENTS OF SCC}

For successful casting of SCC, it is necessary to ensure good balance between excellent deformability, stability, and preventing the blockage of concrete flow. Basic workability requirements of SCC are summarized in Fig. (S). A brief explenation of these requirements are given in the following sections:

\section{High Deformability}

Deformability of concrete is defined as the ability of the concrete to undergo a change in its shape under its own weight, even in the vicinity of obstacles that can interfere with its flow. In order to secure an SCC that can flow readily around various obstacles and achieve good filling capacity, it is important to insure both high flowability and high resistance to segregation (moderate viscosity). The deformability of concrete increases with the incorporation of superplasticizer. Although water and superplasticizer improves the flowability of concrete, but water reduces the viscosity of concrete, while superplasticizer results in a limited drop in viscosity. Therefore, an increase in w/c can provide high deformability, but it can also reduce the cohesiveness of the paste and lead to segregation of fine and coarse aggregate particles, causing blockage of the flow. Hence, a balance is needed 10 increase the $w / c$ to enhance deformability without a substantial reduction in cohesiveness.

Another important parameter that affect deformability is the interparticle friction between the various solids (coarse and fine aggregates and powder materials). The interparticle friction increases when the concrete spreads through restricted spacing because of the greater collision between the various solid. This friction increases the internal resistance to flow, thus limiting the deformability and speed of flow of the fresh concrete. However, the use of superplasticizer disperses cement grains and reduces interparticle friction. Superplasticizer enables the reduction in water content while maintaining the required level of flowability and viscosity. The interparticle friction can also be reduced by the use of well-graded cementitious materials and fillers. Meanwhile, the effect of such filler materials on the workability loss, and temperature rise should be taken into consideration. 


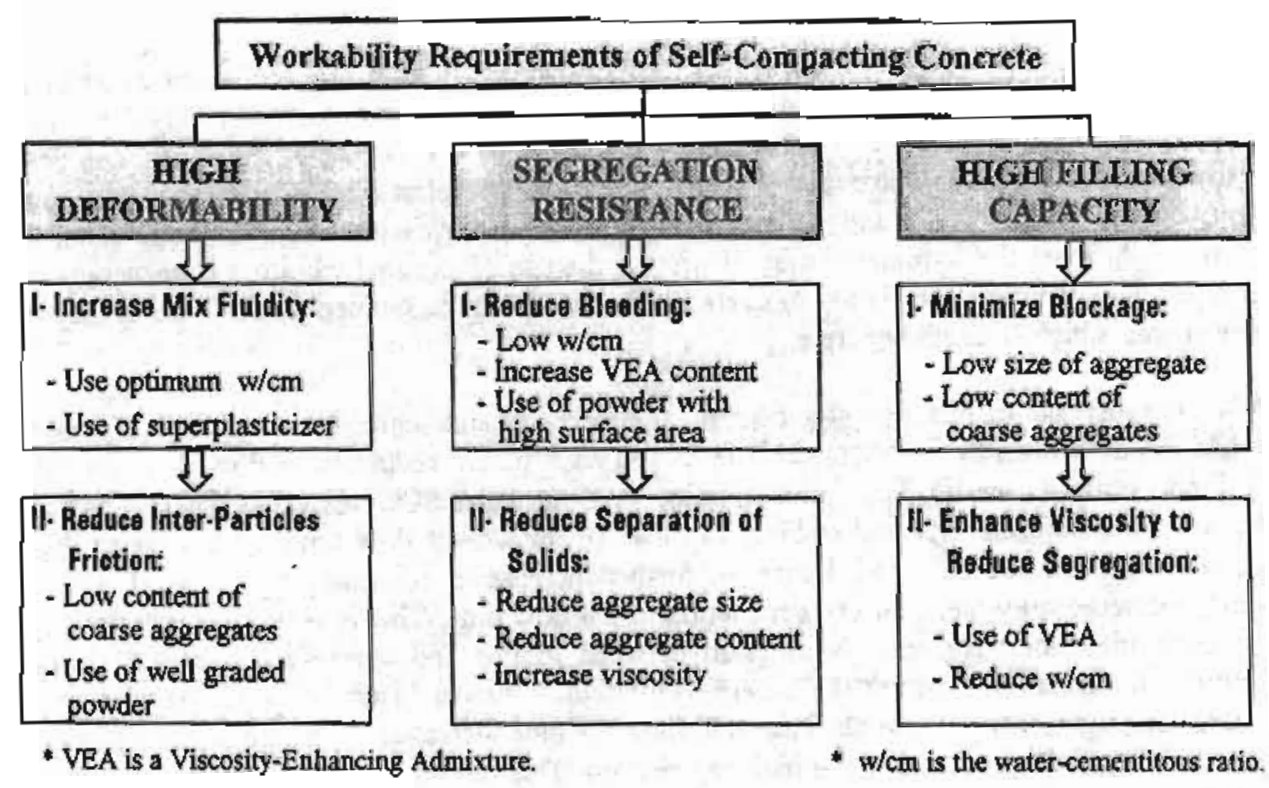

Fig. (5) Basic Workability Requirements of SCC.

\section{Segregation Resistance}

The secund workability requirement necessary to provide SCC is the segregation resistance or the stability of the concrete. As shown in Fig. (5), improvement of segregation resistance involves the reduction in coarse aggregate content and the lowering of the maximum size of aggregate. It is also important to increase cohesion of the mix to enhance bond between the mortar and coarse aggregate, hence providing enough cohesion to insure uniform flow of both phases. Concrete with low cohesiveness can segregate since it can not maintain proper suspension of aggregate to insure uniform deformation around obstacles. As concrete deforms around a restricted section, a portion of the coarse aggregate can begin to segregate, which can result in an increase in aggregate density leading to coagulation and arching of the aggregate, and hence, blockage of the flow. Therefore, when concrete flows through restricted areas, such as between closely spaced reinforcement, it is important to insure that it has sufficient viscosity to maintain uniform suspension of solid particles. However, viscosityenhancing admixture plays an important role in improving concrete stability and preventing segregation. It is also necessary to minimize bleeding of SCC.

\section{High Filling Capacity}

The third requirement essential to produce SCC is the high filling capacity of concrete or, in other words, mitumizing the risk of blockage of concrete resulting from the flow in narrow spaces. To prevent blockage of concrete flow among closely spaced obstacles, concrete should have adequate cohesiveness by reducing the w/c and/or incorporating an adequate dosage of a viscosity-enharicing admixture. Compatibility is necessary between size of coarse aggregate particles and clear spacisg of obstacles in congested section. In addition, well graded powder should be used to reduce inter-particle friction and minimize the risk of blockage. 


\section{Deformability - Stability Interaction}

From the interrelation between workability properties presented in Fig. (6), three zones as I, II, and III may be distinguished. In the first zone, concrete exhibits high viscosity (i.e., high stability) with low deformability. This can be happen when the concrete is proportioned with a low content of mixing water and a given dosage of superplasticizer. Concrete in this zone normally seems sticky, stiff and exhibits a very low slump flow with a high low time under its own weight from the V-funnel outlet. However, the use of external vibrators is necessary for compacting such concrete. Thus, concrete in zone I can not be defined as SCC, but it may be considered a high strength concrete.

With the increase of mixing-water content, the viscosity and segregation resistance decrease while the deformability increases. This results in an apparent reduction in flow time from the V-funnel outlet (zone II). The optimum point for a particular SCC-mix exists where a balance between the deformability and stability can lead to the lowest flow time. At this point, high quality SCC may be achieved. However, further increase in deformability (zone III, Fig. 6) does not necessarily mean an extra reduction in the flow time. This is because highly flowable concrete may not have enough cohesion between mortar and coarse aggregates to insure uniform deformation through the tapered outlet of V-funnel. Thus, a local coagulation of coarse aggregates may cause blockage and the flow time increases. Concrete in zone III has a low stability and aggregates suffer high segregation. This can lead to poor concrete with weak interface between the aggregate and cement paste. There will be a tendency to develop local microcracking that can increase permeability and reduce mechanical properties.

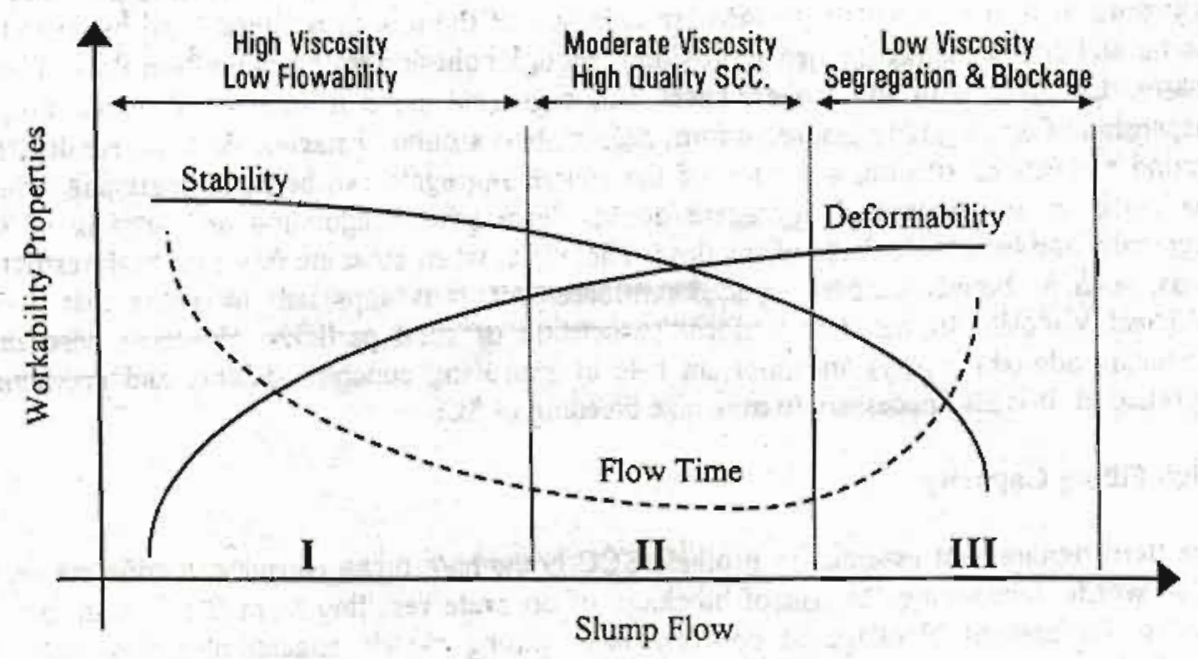

Fig. (6) Offhanded Interrelation Between Workability Properties of SCC. 
Table 2 Test Results of Self-Compacting Concrete.

\begin{tabular}{|c|c|c|c|c|c|c|c|c|c|c|c|c|c|c|c|c|c|c|}
\hline Propeny $\mathrm{Mix}$ & $\bar{\Sigma}$ & $\frac{\pi}{\pi}$ & 3 & 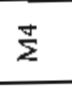 & 3 & 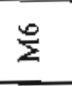 & 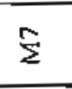 & $\frac{\infty}{\Sigma}$ & $\frac{9}{3}$ & $\frac{9}{2}$ & $\overline{\bar{z}}$ & $\Xi$ & $\frac{m}{\Sigma}$ & $\stackrel{ \pm}{=}$ & $\stackrel{12}{\Sigma}$ & $\frac{0}{\Sigma}$ & $\frac{m}{z}$ & $\sum^{\infty}$ \\
\hline $\mathrm{m}$ & & 26 & 39 & 27 & 26 & & 27 & & & 27 & 27 & & 27 & 27 & 28 & 27 & 27 & 27 \\
\hline n & 46 & 7 & BD & 69 & 68 & 52 & 71 & & 70 & 76 & 60 & 52 & 68 & & 5 & 3 & 7 & 63 \\
\hline$y \cdot y$ & B. & 40 & at & 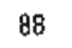 & 7 & 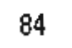 & 100 & 74 & 78 & 96 & 80 & & 90 & 91 & 100 & 90 & 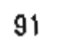 & 88 \\
\hline sec. & 6 & B. & 11 & 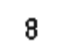 & 20 & 14 & 2 & 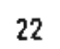 & 8 & If & 12 & & 10 & & & ro & 10 & 25 \\
\hline $28 \cdot \mathrm{MPa}$ & 35 & $n$ & 289 & 27.5 & 28.0 & 27.3 & 36 & 24 & 72 & 30 & & & 20.3 & 35.7 & 17.3 & 14.3 & 11. & 9.9 \\
\hline
\end{tabular}

* $\mathrm{B}=$ Blockage

\section{TEST RESULTS AND DISCUSSION}

In SCC, unlike traditional concrete, a combination of a greater number of constituent materials are used. This is due to the large number of particular properties required in SCC such as deformability, segregation resistance, and passing ability or no blocking of concrete. Test results of fresh concrete properties are given in Table 2 . The values obtained from these tests are quite appropriate for using SCC in any construction site. Fig. (7-a) shows the test results of slump flow of different SCC-mixes. An extensive literature review on the practice and application of SCC was made. There was a general consensus $[2,3,5-8]$ that siump flow should be not less than $600 \mathrm{~mm}$. Accordingly, mixes M1, M5, M6, M8, and M12 which revealed slump-flow values less than $600 \mathrm{~mm}$, may be exeluded from being successful SCC mixes. However, mix M15 exhibited a value of slump flow as bigh as $850 \mathrm{~mm}$. On the other hand, the results of the filling capacity of different SCC mixes are shown in Fig. (7-b). It can be noted that mixes $\mathrm{M} 1, \mathrm{M} 2, \mathrm{M} 3, \mathrm{M} 5, \mathrm{M} 6, \mathrm{M} 8, \mathrm{M} 9$, and M1 l yielded a filling capacity percent less than the recommended-minimum percentage $(85 \%)$. In mix $\mathrm{Ml}$, a blockage of concrete in the filling-capacity box has occurred. This may be due to the bigh content of coarse aggregate in this $\operatorname{mix}\left(0.7 \mathrm{~m}^{3}\right)$ and the absence of any fine materials such as limestone powder or fine sand. Mixes $\mathrm{M} 7$, and M15 resulted in a filling capacity percent as bigh as $100 \%$. Seven different mixes revealed filling capacity percentages greater than or equal $90 \%$. These results may be considered quite appropriate for producing successful $\mathrm{SCC}$.

Fig. (7-c) presents the results of passing time of different $5 \mathrm{CC}$ mixes from $\mathrm{V}$-funnel. For high quality SCC, the passing time should not be greater than 12 seconds [5-8]. The results indicated that, nine different mixes showed higher passing time, while other nine trixes gave good results for passing time ( $\leq 12 \mathrm{sec}$.). Mix M2 exhibited blockage of concrete in the outlet of V-funnel. This reflects the less ability of concrete in this mix to path through a restricted area. On the contrary, mixes M4, M9, M14, and M15 revealed high ability to spread through the outlet of V-finnel $(7 \mathrm{to} 8 \mathrm{sec}$ ). Thus, the three main properties of SCC are slump flow, filling capacity, and passing time. The results of these properties are integrally analyzed It can be noted that, the resulcs of mixes $\mathrm{Ml}$, and M8 are beyond the limitations of SCC. Other mixes such as $M 3, M 7, M 9, M 10, M I l$, and $M 18$ have succeeded to attain the recommended limits of two main properties, but have failed to pass the limits of the third property. Meanwhile, mixes M4, M13, M14, MIS, MI6, and M17 have successfully attained the recommended levels suggested for achieving bigh quality SCC. 


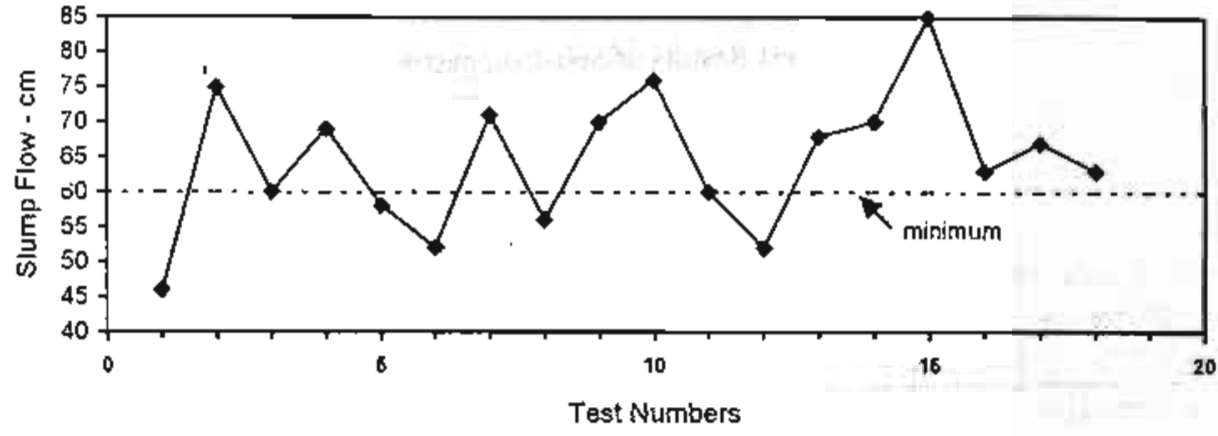

Fig. (7-a) Slump Flow of Different SCC-Mixes..

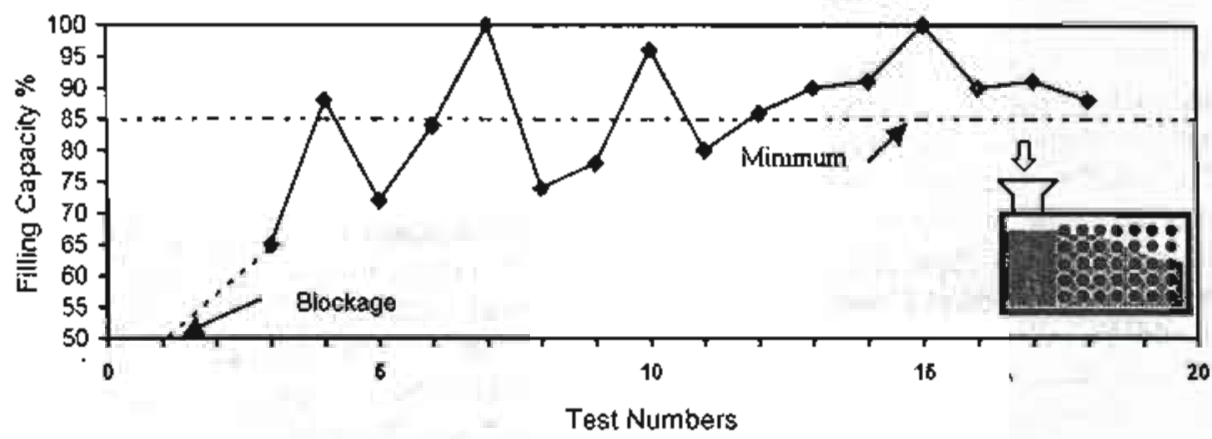

Fig. (7-b) Filling Capacity of Different SCC-Mixes.

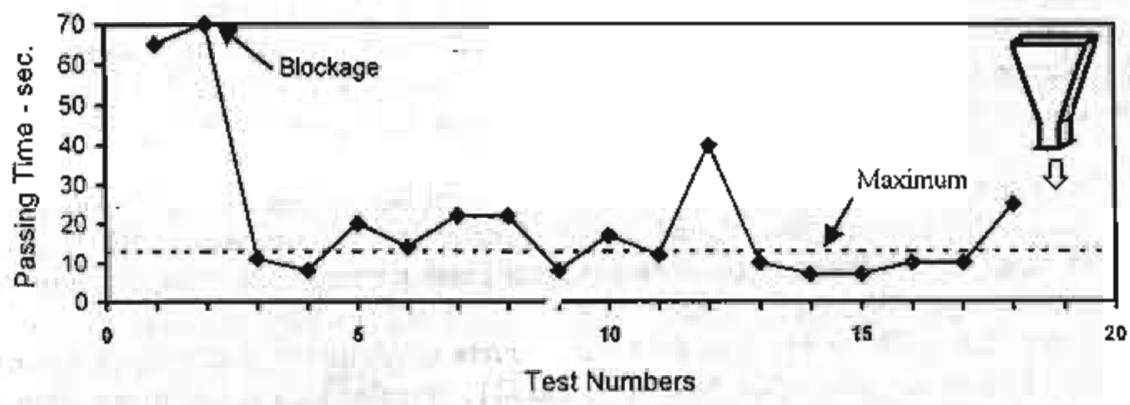

Fig, (7-c) Passing Time of Different SCC-Mixes. 
Fig. (8) presents the effect of lionestone powder fraction on the workability properties of SCC. The contents of limestone powder changed from 0 to $25 \%$ by weight of total aggregates. Sand with a content of $35 \%$ by weight of total aggregates is kept constant in atl mixes, while gravel content was changed according to the change of limestove-powder content. Thus, the total content of both gravel plus limestone powder is always $65 \%$ by weight of total aggregates. Test results indicated that, the use of $15 \%$ of limestone powder (gravel $=50 \%$ ) gave very good results of fresh concrete properties. The recorded filling capacity was $88 \%$, slump flow was $690 \mathrm{~mm}$, and passing time from V-funnel was $8 \mathrm{sec}$. All these results cover the desiredrecommended values suggested for high quality SCC. It is worth noting that blockage of concrete occured for mixes containing limestone powder with content less than $10 \%$ by weight of total aggregates (M1, and M2). When limestone powder with content greater than $15 \%$ was incorporated, the flowability of SCC is getting lower. For example, mixes containing limestone powder with contents of 20 , and $25 \%$ (M5, and M6) yielded slump flow of 580 , and $520 \mathrm{~mm}$ respectively. Thus, it may be concluded that, the optimum content of limestone powder is about $15 \%$ by weight of total aggregates. For 5table SCC-mixes with slump values greater than $250 \mathrm{~mm}$, the slump measurement is not as sensitive as that of the slurmp flow or passing time value in reflecting small changes in the consistency of SCC as shown in Fig. (9-a, b). Within the limited number of mixes in this study (18 mixes), the slump values ranged from 230 to $280 \mathrm{~mm}$ with a coefficient of variation of only $4.15 \%$. The cortesponding range for slump-flow results was 460 to $850 \mathrm{~mm}$ with a variation coefficient of $15.13 \%$, while the passing time ranged from 7 to 65 sec. with a coefficient of variation as high as $81.79 \%$.

Although the attainment of the desired properties of fresh concrete is the most important goal in case of SCC, the compressive strength of hardened concrete still the main property that can not be ignored. The results of 28-days compressive strength of different SCC-mixes are given in Table 2. The compressive strength ranged from 9.9 to $36.3 \mathrm{MPa}$ depending on the proportion of the constituent materials in each mix. It can be noted that, mix $\mathrm{M} 7$ which provided the highest compressive-strength value, passed through the outlet of V-funnel in time as high as $22 \mathrm{sec}$. It can also be noted that, mixes containing air-entraining admixtures (M15 to M18) exhibited compressive strength less than $20 \mathrm{MPa}$. However, mixes which successfully attained the recommended levels of the desired properties of fresh concrete, provided compressive strength in the range from 11.4 to $35.7 \mathrm{MPa}$. The compressive strength of mixes M14 and M4 are 35.7, and 27.9 MPa. These results emphasize the merit of using and utilizing such $\mathrm{SCC}$ mixes in structural purposes.

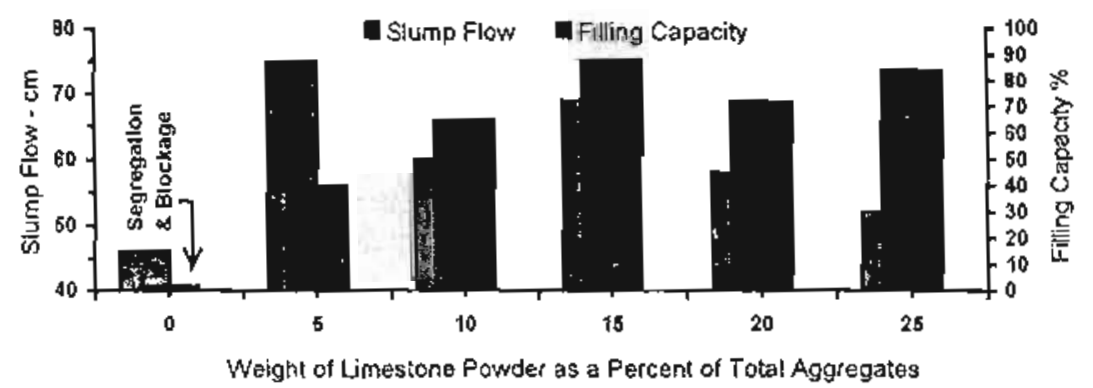

Fig (8) Effect of Limestone-Powder Fraction on SCC 


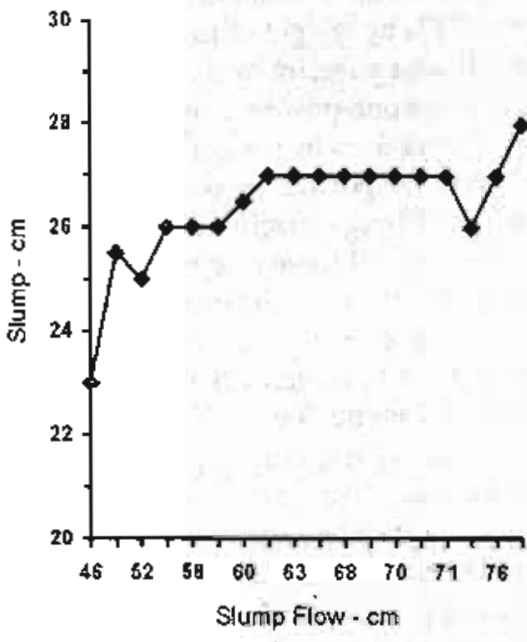

Fig. (9-a) Slump versus Slump-Flow.

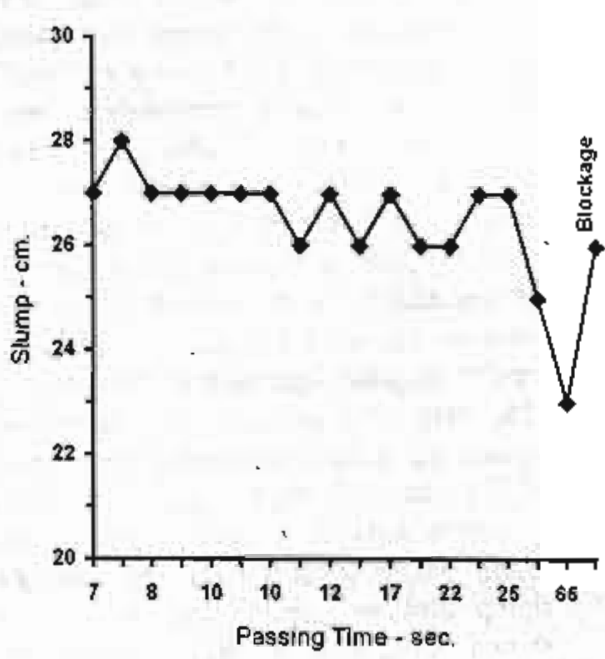

Fig. (९-b) Slump versus Passing-Time.

\section{CONCLUSIONS}

SCC has been successfully produced using available local materials. The proportioning and test results of eighteen different mixes were presented. SCC-mixes provided shump flow up to $850 \mathrm{~mm}$, filling capacity up to $100 \%$, passing time up to $7 \mathrm{sec}$, and compressive strength up to $36.3 \mathrm{MPa}$. SCC offers high deformability, stability, segregation resistance, and high filling capacity with good resistance to blockage upon flowing through congested areas. The findings of this research may be useful to engineers considering the use of SCC to facilitate the casting of congested areas with limited compaction effort or to repair damaged structural sections that present difficulties for concrete placement and consolidation. SCC is believed to be a promising construction material in the near future. Based on the results of the experimental work presented in this paper, the following guidelines are drawn:

1- Viscosity-Enhancing admixture together with the new generation superplasticizer based on a modified polycarboxylic-polyether may be considered the keystone for producing SCC.

2- Despite the higher degree of concrete wetness (w/c up 100.61 ), the incorporation of viscosity-enhancing admixture with a dosage of 0.5 to $1.5 \%$ by weight of cement improved cohesion and provided more uniform flowable concrete.

3- The incorporation of limestone powder with a content of about $15 \%$ by weight of total aggregates (gravel $=50 \%$, and sand $=35 \%$ ) improved segregation resistance and the flowability of SCC. The recorded filling capacity was $88 \%$, slump flow was $690 \mathrm{~mm}$, and passing time from $\mathrm{V}$-funnel was $8 \mathrm{sec}$

4- The use of coarse aggregates with a maximum size not more than $20 \mathrm{~mm}$ and a content less than $55 \%$ by weight of total aggregates is necessary for producing SCC.

5- Although air-entraining admixture improved the desired properties of fresh concrete, it reversely affected the compressive strength of SCC. Thus, when SCC with high sirength is required, air-entraining admixture is not advisable.

6- Three main tests which differentiate SCC from ordinary concrete were carried out and explained in this paper. These tests are slump-flow, V-funnel, and filling-capacity. 


\section{ACKNOWLEDGMENTS}

The author is deeply indebted to the staff members of the laboratory of testing materials. Mansoura university, for their assistance during the conduct of the experimental part of this work. High appreciation and gratitude are due to the company of FOSROC for supplying materials to this research.

\section{REFERENCES}

1- M. Yurugi, N. Sakata, M. Iwai, and G. Sakai "Mix Proportions For Highly Workable Concrete" Proceedings of the International Conference, Concrete 2000, Edited by R. Dhir, and M. Jones, University of Dundee, Scotland, UK, Sept. 1993, pp. 579-589.

2- N. Nagamoto and K. Ozawa "Mixture Properties of Self-Compacting, High-Performance Concrete" American Concrete Institute, SP 172-33, edited by V. Mathotra, pp. 623-636.

3- H. Kim, Y. Park, Y. Song, C. Han, and S. Kang "Rheological Properties of SelfCompacting High-Performance Concrete" American Concrete Institute, SP 172-35, edited by V. Malhotra, pp. 653-668.

4- Proceedings of the first International RILEM Symposium on Self-Compacting Concrete, Stockhoim, Sweden, 1999.

5- R. Khurana, and O. Topcu "Role of Superplasticizers in the Development of Self Compacting Concrete" Proceedings of the $2^{\text {nd }}$ International Symposium on Cement and Concrete Technology in the 2000s, Sept. 2000, Istanbul, Turkey, pp. 473-482.

6- O. Topcu, A. Saglik, I. Cil, M. Inal, S. Polat, A.Uste, "Applications of Self-Compacting Concrete in Common Building Structure - A Case Study." Proceedings of the 2nd International Symposium on Cement and Concrete Technology in the 2000s, Sept. 2000, Istanbul, Turkey, pp. 483-492.

7- M. Hulusi, U. Dogan, Z. Cavdar, A. Saglam, and N. Parlak "Effects of Self-Compacting Concrete Admixtures on Fresh and Hardened Concrete Properties" Proceedings of the 2nd International Symposium on Cement and Concrete Technology in the 2000s, Sept. 2000, Istanbul, Turkey, pp. 493-502.

8- K. Khayat "Workability, Testing, and Performance of Self-Consolidating Concrete" ACI Materials Journal, V. 96, No. 3, May-June 1999, pp. 346-353

9- K Khayat "Optimization and Performance of Air-Entrained, Self-Consolidating Codcrete" ACl Materials Journal, V. 97, No, 5, September-October 2000, pp. 526-535.

10- K. Khayat "Frost Durability of Concrete Containing Viscosity-Modifying Admixtures" ACI Materials Journal, V. 92, No. 6, November-December 1995, pp. 625-633.

II- K. Khayat, K. Manai, and A. Trudel "In Situ Mechanical Properties of Wall Elements Cast using Self-Consolidating Concrete" ACl Materials Journal, V. 94, Na. 6, NovemberDecember 1997, pp. 491-500.

12- K. Khayat, and Z. Guizani "Use of Viscosity-Modifying Admixtures to Enbance Stability of Fluid Concrete" ACI Materials Joumal, V 94, No. 4, July-August 1997, pp. 332-340.

13- J. Kim, and S. Han "Mechanical Properties of Self-Flowing Concrete" American Concrete Institute, SP 172-34, edited by V. Malhotra, pp. 637-652.

14- N. Mura, N. Takeda, R. Chikamatsu, and S Sogo "Application of Super Workable Concrete to Reinforced Concrete Structures with Difficult Construction Conditions" Anerican Concrete Institute, SP 140-8, edited by Paul Zia, pp. 163-186 
15- K. Kato, S. Yang, and M. Kunishima "A Comparative Study on The Constructability of Self-Placeable Concrete" Proceedings of the International Conference. Concrete 2000 , Edited by R. Dhir, and M. Jones, University of Dundee, Scotland, UK, Sept. 1993, pp. $881-890$.

16- I. Sakamoto, Y. Matsuoka, and S. Tangtermsirikul "Application of Super-Workable Concrete To Actual Construction" Proceedings of the International Conference, Concrete 2000, Edited by R Dhir, and M. Jones, University of Dundee, Scotland, UK, Sept. 1993, pp. $891-902$.

17. H Takeuchi, M. Higuchi, and A. Nanni "Applications of Flowable Concrete in a Tunnel Lining" Concrete International, April 1994, pp. 26-29.

18- 1., Michael, and J., Philippe, "Self-Compacting Concrete - Expanding the Possibilities of Concrete Design and Placement" Concrete International, April 2000, pp. $31-34$. 